\title{
Ancestors of the Archives
}

\author{
BERNARD VALMAN
}

In Europe and America specialist physicians, national societies, and journals devoted exclusively to the medical care of children were well established by the end of the last century. In Britain a few physicians would give an opinion on a sick child while retaining their interest in the medicine of the adult.

In 1896 an attempt was made to start an AngloAmerican journal of children's diseases to be published simultaneously here and in America. The English edition of Pediatrics was not a financial success and was abandoned after a short time. The American publication grew rapidly despite the prestigious Archives of Pediatrics that had been published by the American Pediatric Society since 1884. The name of Archives of Pediatrics was changed to Clinical Pediatrics in 1926 and the last volume was published in 1930 . Perhaps the change to a more modern and snappy title was a factor in the dissolution.

In England 'The Society for the Study of Disease in Children' was started in 1900. Clinical material for the meetings was largely supplied by physicians who worked mainly with children, but a large number of general practitioners attended the meetings, which were held in Brighton and Folkestone as well as Birmingham and London. Dr George Carpenter, who was Physician to the Evelina Hospital, London, edited an annual report for the Society, which was published by $\mathrm{J}$ and A Churchill. It was a substantial volume containing not only the results of papers on recent research but also clinical and pathological observations and the criticisms of the papers that had been heard at the meetings. Carpenter had probably been chosen as Editor because he had been appointed the English Editor of Pediatrics and had remained a member of the Editorial Board after the London edition ceased publication. These reports appeared annually until 1908 when the Society was incorporated into the Royal Society of Medicine.

Carpenter was elected Physician to the North Eastern Hospital for Sick Children, which later became The Queen Elizabeth Hospital for Children in Hackney Road, London (1903). At the same time he held the post of Medical Officer of Health for Beckenham. This was probably the reason for his special interest in the social aspects of children.

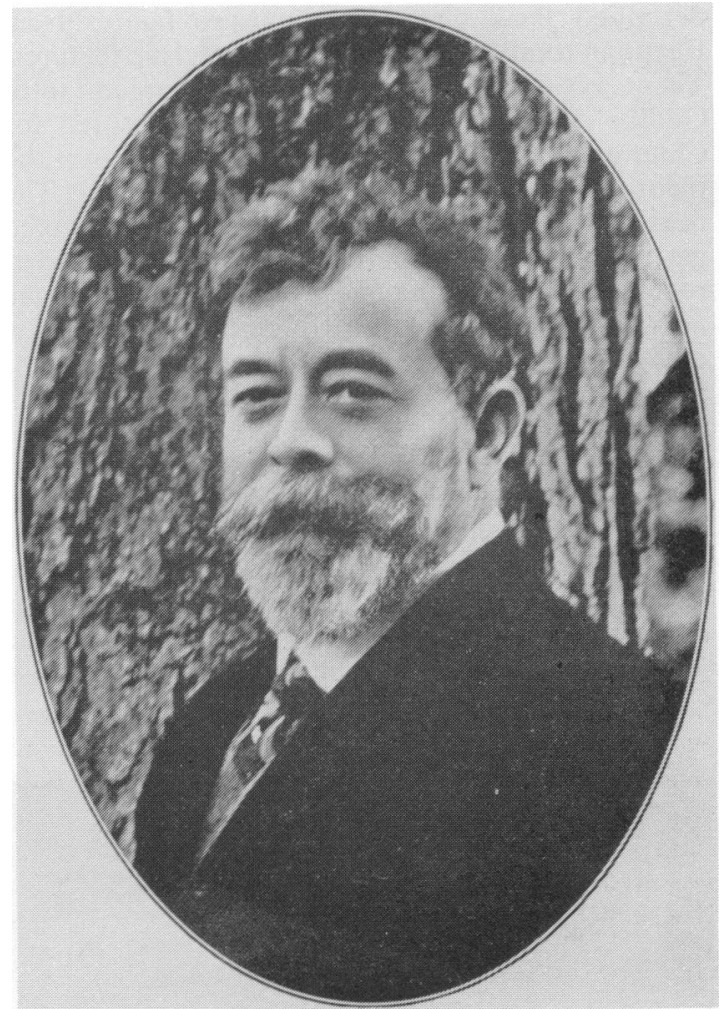

George Carpenter, MD

About this time he saved the life of a child of R E Adlard, a printer, who agreed to finance and print a new paediatric journal with Carpenter as the Editor.

The British Journal of Children's Diseases first appeared in 1904. In the first editorial Carpenter wrote 'The object of the Journal will be to keep its readers in touch with the advances in knowledge in all that relates to the study of disease in children, whether of a scientific or practical nature. Its pages will not only be devoted to the study of disease in children, but to the prevention of disease, and to all that appertains to the welfare of children, whether physical or psychical. If The Society for the Study of Disease in Children and The British Journal of Children's Diseases can accomplish this good end, 
they will not only have justified their existence, but they will have accomplished a very worthy mission.'

The first paper was a case of hemicrania with third nerve paralysis by James Taylor, who was Physician to The National Hospital, Queen's Square. The second was a note on the antiquity of achondroplasia by George Pernet, who was Assistant to the Skin Department at University College Hospital, and described small glazed earthenware figures from Egyptian tombs showing the characteristic features. There was an article by Mr Clifford, Surgeon to St George's Hospital and the Belgrave Hospital for Children, on congenital hypertrophic stenosis of the pylorus in which pyloroplasty was performed. The next day the infant fed well but then developed gastroenteritis, a feature that was to be described at regular intervals in the pages of the Journal for the next 30 years. Mr Harold Burroughs described a case of Henoch's purpura in which a laparotomy was performed, and an accompanying editorial was on the aetiology of the visceral crises in Henoch's purpura. There was an editorial on the Employment of Children's Act and abstracts from the current literature, including a new treatment for whooping cough and the vitality of children of tabetics. In the signed book review section an author is rebuked for giving general practitioners confusing advice. The author had listed the treatment for a restless case

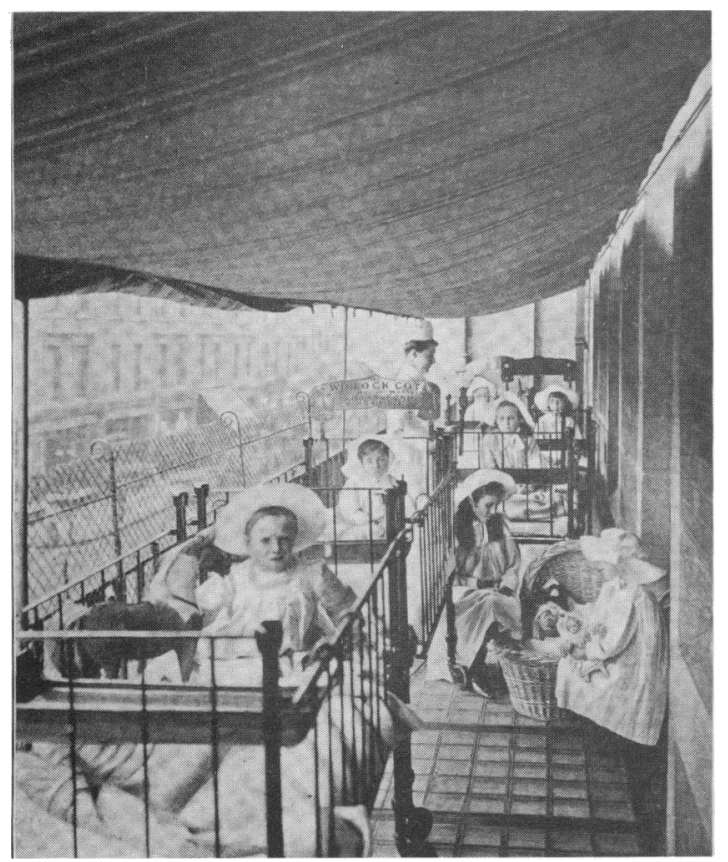

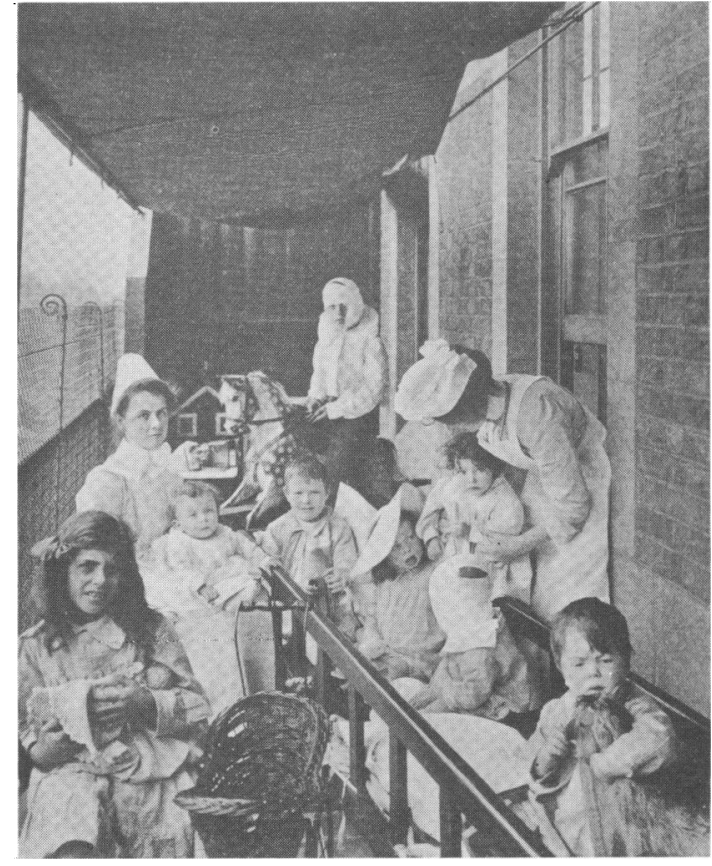

Open air treatment at the North Eastern Hospital for Children: medical balcony (below, left) and surgical balcony (above).

of pneumonia as the following: 'Two leeches; a small blister; equal parts of chloroform belladonna and aconite liniments applied on lint; the ice bag; and cold lotions. The warm applications will generally be found to be the best. One, two, or three drops of nepenthe, one to three grains of Dover's powder or a small hypodermic injection of morphia'.

Carpenter wrote most of the editorials in a sparkling style covering many important aspects of the prevention and practical management of disease. He tackled the care of infants in workhouses, the high infant mortality and the new treatment of infectious diseases by exposure to fresh air (Figures). He presented and wrote up a large proportion of the patients presented at clinical meetings. He wrote three books; 'Congenital Affections of the Heart', 'Congenital Syphillis in Children in Everyday Practice', and 'Golden Rules for Diseases of Children'. Within a year he had formed an Editorial Board with six members elected from different parts of the country and two members from abroad. In March 1910 at the age of 50 years he died from a sudden cerebral haemorrhage.

Dr John Davey Rolleston, younger brother of the physician Sir Humphrey, became the next Editor and remained in that post for the next 34 years. He 
was Superintendent of the Western Fever Hospital in London and author of the standard textbook on acute infectious diseases. Although he had immense experience of the care of sick children, he was never recognised as a children's specialist. He continued Carpenter's policy of emphasising the social and practical aspects of the medical care of children as well as the description of physical disease. The number of pages printed gradually diminished to about 300 each year in the 1920 s from 600 in Carpenter's day. The last volume in 1944 had only 66 pages. There was an original article on meningitis in children refractory to sulphonamides and a paper on the pathogenesis and clinical symptoms of tuberculous meningitis. In the final edition there were abstracts of a 1939 meeting (held five years previously) of the Royal Society of Medicine where there were presentations of kernicterus by $\mathrm{Dr} R \mathrm{~S}$ Illingworth, diabetes insipidus by Dr Donald Court, and subdural haematoma by Mr D W C Northfield. The Editor must have been desperate for material at this time because he then published an account of a meeting held 11 years earlier in 1933 at the Societié de Pédiatrie of Paris, a Society whose meetings Carpenter had attended regularly and reported promptly.

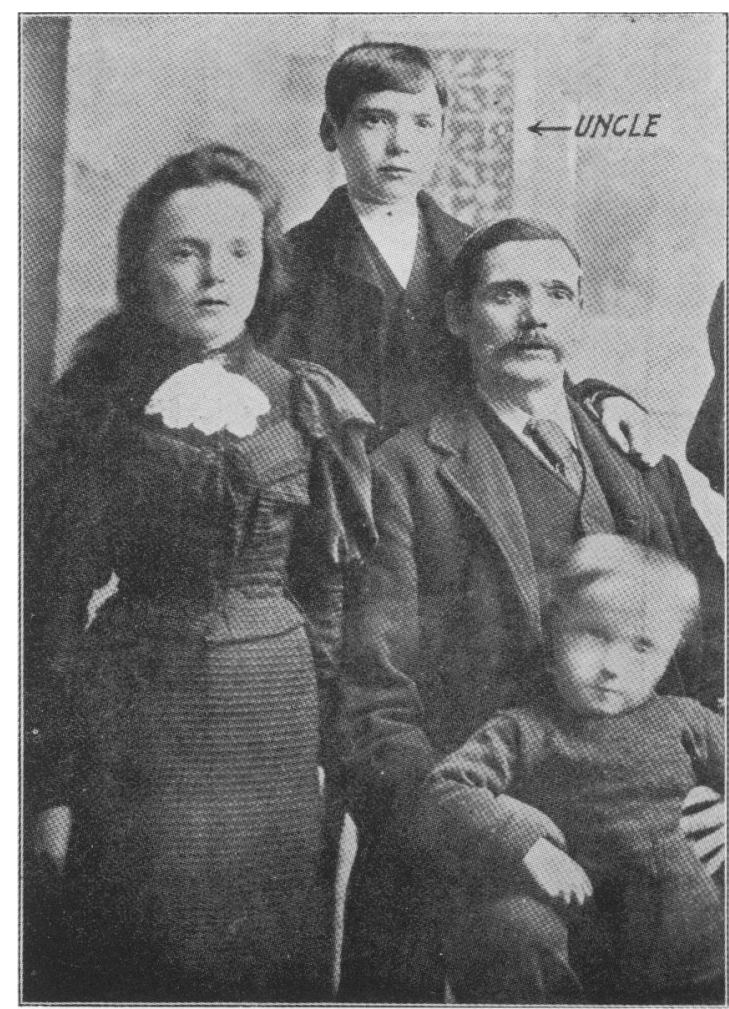

Photograph of the family of the case of hypertelorism reported in the 1926 Archives volume 1. 